\title{
Multivariate Panel Cointegration Models and Money Demand Function
}

\author{
Chien-Chiang Lee ${ }^{1}$; Chun-Ping Chang, ${ }^{2}$ \\ 1.Chien-Chiang Lee. Department of Applied Economics, National Chung Hsing University, Taichung, \\ Taiwan 402. Email: ccl@nchu.edu.tw. \\ 2.Chun-Ping Chang, Corresponding author. Institute of Interdisciplinary Studies for Social Science, \\ National Sun Yat-sen University, Kaohsiung, Taiwan. Email: k091955@mail3.kh.usc.edu.tw.
}

\begin{abstract}
Is just only one cointegrating vector among the panel variables? Based on the multivariate maximum likelihood cointegration tests offered by Larsson et al. (2001), the findings here provide solid evidence of the presence of at least two cointegrated vectors for the money demand function in GCC countries,
\end{abstract}

\section{Introduction}

Owing to the panel cointegration method provides more powerful tests and estimates, while allowing us to increase the amount of information available from cross-sections. It also enables us to estimate long-run relationships linking the variables in the cointegration tests as well as estimate and permits heterogeneity among individual members of the panel (Perman and Stern, 2003; Pedroni, 2004). Thus, there is a huge amount of literature on the various issues concerning long-run equilibrium between economic variables using the panel cointegration test. However, limited by the unity cointegratedg vector, it may be a fallacy but unavoidable performances- in these studies are probably the most imperfect. As concerns the suggestions from Larsson et al. (2001) as well as Ericsson and Irandoust (2004), the various panel tests for cointegration are, in essence, univariate extensions of the original panel unit root tests based on residuals from a first-step cointegrated regression in the spirit of the two-step cointegrated testing approach from Engle and

Granger (1987).

A weakness inherent to these tests is that they assume the cointegrated vector is equal to unity. It is very probable that not only one cointegrating vector exists among the panel variables (Larsson, et al., 2001). To overcome this, systematic estimation methods have been suggested by Larsson et al. (2001) who propose panel cointegrated tests analogous to the Johansen (1988, 1995) maximum likelihood method. Larsson et al. (2001) provide a likelihood-based panel test of the cointegrated rank and a general likelihood-based framework for inference in panel-VAR models with cointegration restrictions that allow for multiple cointegrated vectors. In a word, the likelihood-based panel test for cointegration rank in heterogeneous panel models is based on the average of individual rank trace statistics. Therefore, the assumption of a unique cointegrating vector and the problem of normalization are relaxed when this approach is used. ${ }^{1}$ The purpose of this paper, therefore, is to

1 Recently, Ericsson and Irandoust (2004) have used the likelihood-based panel cointegrated approach to test the PPP hypothesis. 
determine the panel cointegrated relation between the money demand function (MDF) and the variables of real money balance, the real scale variable, the nominal interest rate and the exchange rate for six selected Gulf Cooperation Council (GCC) countries. We use the four-dimensional dynamic vector error correction model (VECM). These countries in this study are Bahrain, Kuwait, Oman, Qatar, Saudi Arabia and the United Arab Emirates (UAE).

\section{Empirical Results}

For comparing with Harb (2004), the data we use in this study are annual, cover six of the GCC countries and run from 1979 to $2000 .^{2}$ To determine whether there is a long-run relationship between the MDF variables for these GCC countries, we test for panel cointegration among them under the condition that all the MDF series are integrated of order one. ${ }^{3}$ Next, we test for panel cointegration based on panel VAR models, as suggested by Larsson et al. (2001) and Larsson and Lyhagen (1999) and estimate the following MDF equation: $m_{i t}=\beta_{i 0}+\beta_{i 1} y_{i t}+\beta_{i 2} r_{i t}+\beta_{i 3} x_{i t}+\varepsilon_{i t}$ (1)

where $i$ refers to a given member in the panel; $m_{i t}$ and $y_{i t}$ are respectively the natural logarithm of real M1 (RM1) and the real scale variable GDP (RGDP), divided by the corresponding consumer price index which represents the economic activity for country $i$. $x_{i t}$ is the nominal exchange rate (EXC, local

\footnotetext{
2 We are greatly appreciative of Professor Harb's willingness to provide us with the data.

3 Harb (2004) has applied the panel unit root tests and has pointed out that all variables are I(1).
}

currency per unit of Special Drawing Right (SDR) since they have a fixed peg to the U.S. dollar), $r_{i t}$ is the nominal interest rate which represents the opportunity cost of holding money, and $\varepsilon_{i t}$ is iid. To parallel Larsson et al.'s model, the four variables in the model are expected to be non-stationary and cointegrated, with $\left\{1,-\beta_{i 1},-\beta_{i 2}\right.$ and $\left.-\beta_{i 3}\right\}$ as the cointegration vectors. The lags we select are determined by minimizing the Schwarz Bayesian information criteria.

Table 1 reports the individual country-by-country and panel test results, and there appears to be a reasonable fit in terms of the test statistics for normality and autocorrelation. The trace statistics are also reported in Table 1. The country-by-country individual trace statistics indicates the presence of a cointegrating vector equal to 1 (Kuwait, Oman and Saudi Arabia) or zero (Bahrain, Qatar and the United Arab Emirates). However, these results are confirmed by the panel cointegration test shown at the bottom of the table. In fact, the most common rank in the panel is $r=2$. Hence, the Larsson et al. (2001) panel test suggests the presence of at least two cointegrating vectors for the money demand function in these GCC countries though Harb (2004) has only found one cointegrating relationship based on same data source. Overall, using the panel cointetegrating test, our study identifies the long-run stability relation in the MDF in these GCC countries, which indicates the authorities in the Gulf should use M1 as the main target of its monetary policy.

The standardized coefficients of the variables entering into the respective 
cointegrated vectors are presented in Table 2. To facilitate an economic interpretation of these results, we normalize the cointegrated vectors of real $\mathrm{M} 1$, and the resulting value is the long-run elasticities. Next, the coefficient restriction test which determines that the full panel test significantly rejects the hypothesis of the quantity theory of money for the long-run elasticity of income equal to unity and that the semi-elasticity of the interest rate and exchange rate are equal to zero in the six GCC countries. On account of the complete test procedure, we need to further put forward the panel cointegrated relationship with each variable among the MDF in the GCC region to link with the convenience of policy conduction. In particular, we need to focus on factors that influence the money supply of each of the GCC economies.

\section{Conclusion}

We adopt the new technique, the multivariate maximum likelihood cointegration test, in pursuit of shedding light on the MDF in GCC countries, the findings provide more evidences of the presence of at least two cointegrated vectors for the MDF in GCC countries. This indicates the central bank should use real M1 as the main target of its monetary policy. At the center of focus of this study is the discussion of the regional money demand phenomenon and the challenges its adoption faces as well as the potential benefits of monetary integration for these GCC members.

\section{Reference}

[1] Engle, R. F., and C. W. J. Granger (1987). Co-integration and Error Correction: Representation, Estimation, and Testing.
Econometrica 55: 251-276.

[2] Ericsson, J., and M. Irandoust (2004), The Productivity-Bias Hypothesis and the PPP Theorem: New Evidence from Panel Vector Autoregressive Models. Japan and the World Economy 16: 121-138.

[3] Harb, N. (2004). Money Demand Function: A Heterogeneous Panel Application. Applied Economics Letters 11: 551-555.

[4] Johansen, S. (1988). Statistical Analysis of Cointegrating Vectors. Journal of Economic Dynamics and Control 12: 231-254.

[5] Johansen, S. (1995). Likelihood-Based Inference in Co-integrated Vector Autoregressive Models. Oxford: University Press.

[6] Larsson, R., and J. Lyhagen (1999). Likelihood-Based Inference in Multivariate Panel Cointegration Models. Working Paper series in Economics and Finance, No.331, Stockholm School of Economics.

[7] Larsson, R., J. Lyhagen, and M. Lothgren (2001). Likelihood-Based Cointegration Tests in Heterogeneous Panels. Econometrics Journal 4: 109-142.

[8] Pedroni, P. (2004). Panel Cointegration: Asymptotic and Finite Sample Properties of Pooled Time Series Tests with an Application to the PPP Hypothesis. Econometric Theory 20 (3): 597-625.

[9] Perman, R. S., and D. I. Stern (2003). Evidence from Panel Unit Root and Cointegration Tests that the Environmental Kuznets Curve Does Not Exist. Australian Journal of Agricultural and Resource Economics 47 (3): 325-347. 
Table 1: Larsson et al.'s (2001) Panel Cointegration Test Notes:

\begin{tabular}{|l|c|c|c|c|c|}
\hline Country & LM(1) & $\mathrm{r}=0$ & $\mathrm{r}=1$ & $\mathrm{r}=2$ & Rank \\
\hline Bahrain & 19.0 & 35.8 & 15.9 & 6.6 & 0 \\
\hline Kuwait & 14.6 & $58.9 * *$ & 12.9 & 2.7 & 1 \\
\hline Oman & 11.3 & $47.3 * *$ & 25.2 & 13.1 & 1 \\
\hline Qatar & 21.7 & 33.3 & 8.0 & 1.5 & 0 \\
\hline Saudi & 19.8 & $58.4 * *$ & 28.0 & 4.1 & 1 \\
Arabia & & & & & 0 \\
\hline UAE & 19.1 & 37.2 & 20.5 & 5.7 & 0 \\
\hline \multicolumn{5}{|c|}{ Panel tests } \\
\hline$Z_{\text {LR }}$ & $6.3 * *$ & $1.7 * *$ & -0.3 & 2 \\
\hline
\end{tabular}

Notes:

1. The panel rank test has a critical value of $1.645 . * *$ indicates significance at the $5 \%$ level. The selected lag is 1 in all countries.

2. The critical values for the trace test at the $95 \%$ significance level are $46.52(\mathrm{r}=0) ; 28.11(\mathrm{r}=1)$ and $14.66(\mathrm{r}=2)$. The 5\% finite-sample critical values are constructed from the asymptotic critical values from MacKinnon et al. (1999) employing the method of Cheung and Lai (1993).

3. $\mathrm{LM}(\mathrm{k})$ is the Lagrange-multiplier test for residual autocorrelation of order k. $Z_{\overline{\mathrm{LR}}}=(\mathrm{H}(\mathrm{r}) / \mathrm{H}(4))$

Table 2: Larsson et al.'s (2001) Panel Test for Coefficient Restrictions

\begin{tabular}{|l|l|c|c|c|}
\hline Country & $\begin{array}{l}\text { Estimated } \beta \\
\text { vector }\end{array}$ & $\beta=1$ & $\beta=2$ & $\beta=3$ \\
\hline Bahrain & $(1,-0.6,0.1,0.4)$ & $10.6^{* *}$ & $10.4^{* *}$ & 0.6 \\
\hline Kuwait & $(1,-0.6,-0.1,1.4)$ & $35.1^{* *}$ & $30.1^{* *}$ & $30.5^{* *}$ \\
\hline Oman & $(1,-0.6,0.1,1.07)$ & $5.9^{* *}$ & 2.8 & 2.9 \\
\hline Qatar & $(1,-2.8,0.7,1.3)$ & $5.0^{* *}$ & $15.8^{* *}$ & $13.1^{* *}$ \\
\hline $\begin{array}{l}\text { Saudi } \\
\text { Arabia }\end{array}$ & $(1,0.1,0.2,-0.2)$ & 1.3 & $4.7^{* *}$ & $4.6^{* *}$ \\
\hline UAE & $(1,1.5,0.1,-1.3)$ & 0.1 & 0.1 & 0.4 \\
\hline $\begin{array}{l}\text { Panel } \\
\text { tests }\end{array}$ & & $58.3^{* *}$ & $64.1^{* *}$ & $52.3^{* *}$ \\
\hline
\end{tabular}

